\title{
Research On The New Generation Smart Substation
}

\section{TAO Jing, HUANG Zaichao, DENG Hui, WANG Wei, CHEN Lei, SHEN Wen}

State Grid Smart Grid Research Institute Nanjing, China

taojing@sgri.sgcc.com.cn

Keywords: smart grid; new generation smart substation; IEC 61850

\begin{abstract}
Smart substation is an important foundation and support for the strong smart grid. It is the data collection source of grid running, and also the execution unit of grid command. This article describes the basics of the new generation smart substation, and analyzes the differences between the structures of conventional smart substation and the new one. The development target of the new generation smart substation and the emphasis of the recent and long-term development are introduced too.
\end{abstract}

\section{Introduction}

Smart substation is an important part of smart grid, it's the key support point for every part of information exchange in grid operation, such as power generation, transmission, substation, distribution, electricity and scheduling. ${ }^{[1]}$

The information network inside the substation which based on the IEC 61850 standard provides high-speed switch Ethernet for the substation automation system. The network meets the information exchange needs of the function devices, such as protection, monitoring, control and measurement equipments.

The communication networks outside the substation convergences and accesses the distributed power, power distribution automation, smart power and other information. And the network provides transmission channels to exchange data between different smart substations, and also between smart substations and regulation masters. ${ }^{[2]}$

\section{The Definition Of New Generation Smart Substation}

Smart Substation. Smart substation is composed by advanced, reliable, energy-saving, environmentally friendly, integrated devices. It completes the basic functions automatically, include the information collection, measurement, control, protection, measurement and monitoring. If necessary, smart substation can also support the grid in real-time automatic control, smart regulation, online analytical decision-making, collaborative interaction and other advanced applications. ${ }^{[3]}$

New Generation Smart Substation. To achieve these goals: "highly integrated system, reasonable structure, advanced equipment, energy saving and environmental protection”, The State Grid Corporation launched the design and construction of new generation smart substation in 2012. The new generation smart substation optimizes the main wiring and layout from design, equipment and control technology, and ultimately improves the overall design of the substation. The smart substation adopts the integrated design of primary equipment, sensor and intelligent components to integrate function of equipments. The new generation smart substation integrates the existing multiple systems and uses hierarchical protection control system, and also deepen and optimize the application of technologies for secondary system control. The new generation smart substation has less occupied area, lower cost and higher reliability than the existing substation. 


\section{What's Different}

The smart substation system is divided into three levels: the process level, the bay level, and the station level. ${ }^{[4]}$

The process level which composed by primary equipment, merging unit and smart terminal completes the following functions: distribution, transformation, transmission, measurement, control, protection and monitoring.

The bay level devices generally refer to protection devices, monitoring and control devices, fault recording equipment and other secondary equipment, and communicate with various remote input/output, smart sensors and controllers.

The station level contains the following these subsystem: the system server, measurement and control system, protection system, automation system, station area control system, communication system and synchronization subsystem and so on. The station level completes measurement and control function for the whole station or primary equipments, and also these functions: the completion of data, monitoring system (SCADA), latching and synchronized phasor acquisition, electric energy acquisition, protection information management etc.

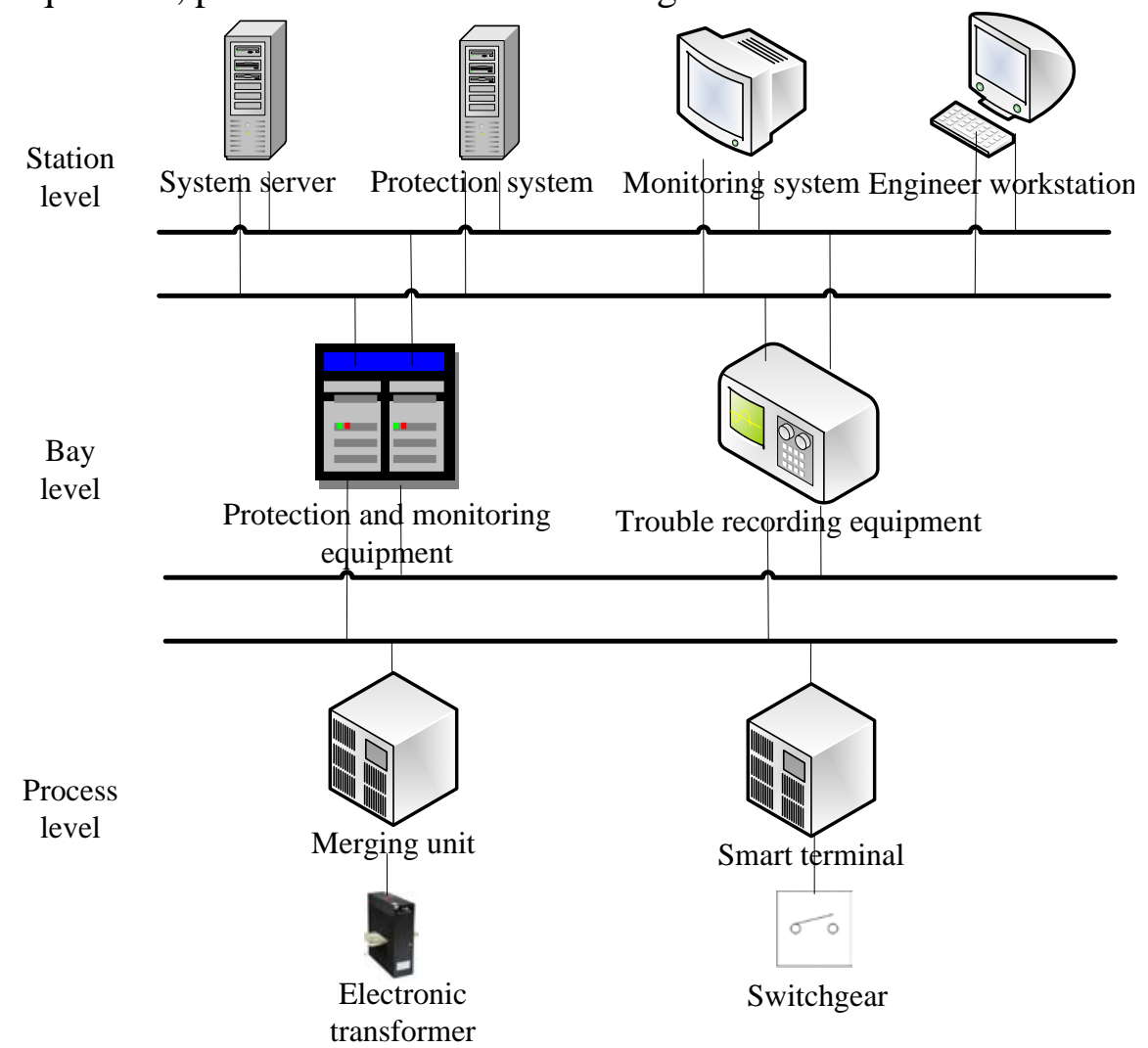

Figure1 The architecture of the conventional smart Substation.

The new generation smart substation system is divided into three levels: the WAN level, the station level and the local level. ${ }^{[5]}$

The local level contains the original process level and bay level. Most function of the bay devices integrate into the smart primary equipment gradually. The acquisition, processing, decision and control information which carried on the existing process level network will access the internal communication bus of the smart equipment. The external interface is only one power cable and one communication line.

The station level simplifies the substation information network, and enhances the performance to reduce complexity of network. And also reduces the number of switches, improves the efficiency of equipments, reduces workload of operation and maintenance. Ultimately meets the construction needs of unattended stations.

The new generation smart substation establishes an integrated information platform to protect the station area, and wide area and control and other advanced applications. 


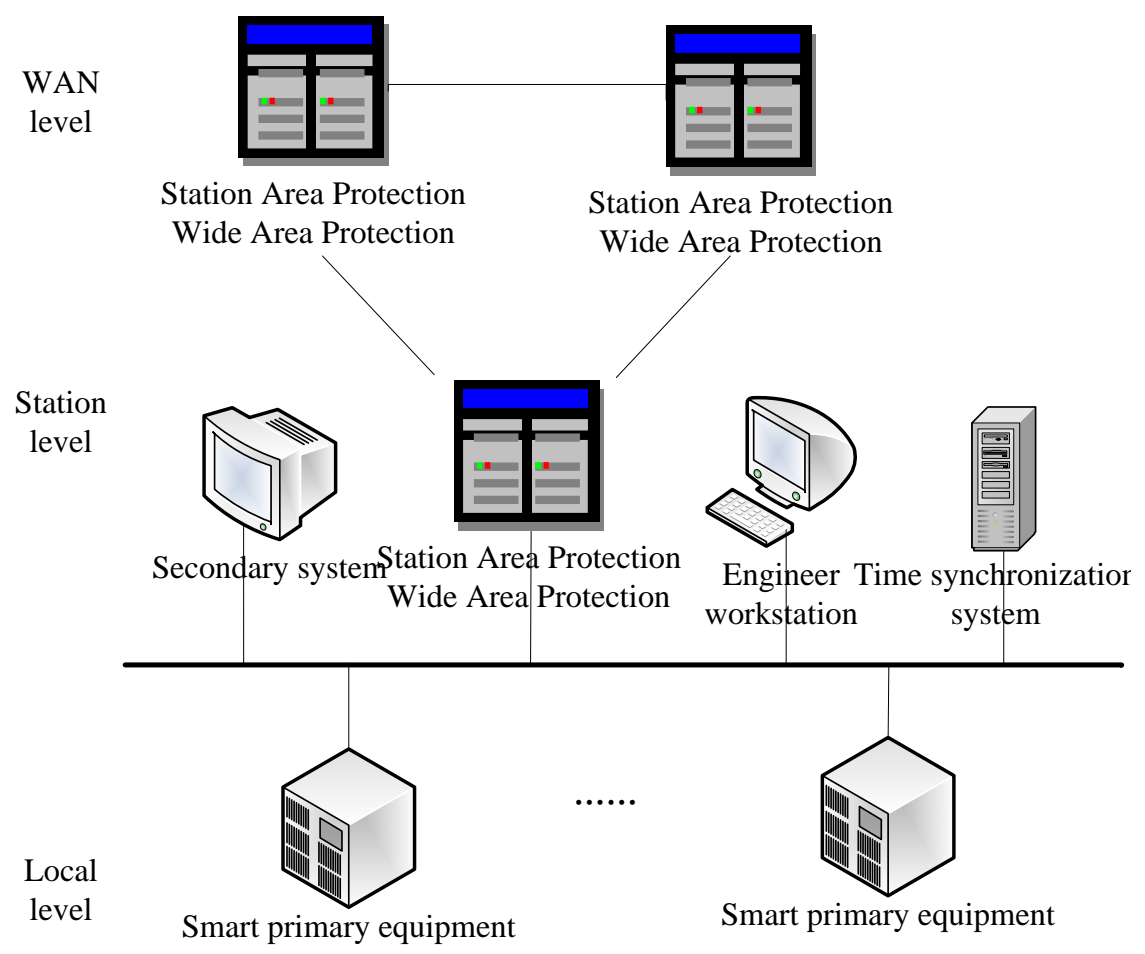

Figrue2 The architecture of new generation conventional smart Substation.

In summary, the conventional Smart Substation and the new generation Smart Substation is as follows:

Table 1. The differences

\begin{tabular}{|l|l|c|}
\hline & \multicolumn{1}{|c|}{$\begin{array}{c}\text { The conventional Smart } \\
\text { Substation }\end{array}$} & $\begin{array}{c}\text { The new generation of Smart } \\
\text { Substation }\end{array}$ \\
\hline $\begin{array}{l}\text { Information } \\
\text { sharing }\end{array}$ & complete & not complete \\
\hline Relay protection & dispersible & hierarchical \\
\hline Automation & collect information repeatedly & collect information uniformly \\
\hline $\begin{array}{l}\text { Systems } \\
\text { Integration }\end{array}$ & inadequate & streamlined \\
\hline
\end{tabular}

\section{Development Plan}

The new generation smart substation changes the focus from primary equipments intellectualization to smart primary equipment. The smart components, sensors and primary equipments are integrated to improve the effectiveness of equipments, and to reduce the difficulty of installation and maintenance.

Recently, the development goal of the new generation of Smart Substation focus on integrating and upgrading the design to support management reform. The technology of integrated equipment, integrated network and integrated system is adopted to improve the reliability level of the substation. It is expected that fault probability of substation will be decreased by about $25 \%$ on average, the average duration of outage time will be reduced by $15 \%$, unavailability of equipment maintenance from 3.1 hours / year will be reduced to 1.2 hours / year, and covers an area of will be reduced by $30 \%$ to $50 \%$. Integrated service platform and protection systems are built to coordinate the control of space and time. The cost will be the same as conventional smart substation or even lower.

In the future, the development goal of the new generation of Smart Substation focus on promoting technological change to show the concept of innovation. Building the new generation smart 
substation with new equipment, materials and technology enable the power can be controlled faster and more flexible.

\section{Conclusion}

As one of the basic link of the smart grid, the smart substation is a energy transfer hub of the smart grid. It's where the main source of operation information come from, where the intelligent operation be carried out.

The new generation smart substation absorbs advanced design concepts and puts more effort into integration and optimization of functions to meet new management needs. At the same time, the new generation smart substation optimizes the function that support the integration debugging control and increases the investment on equipment R \& D to meet the needs that the design is optimized and the functions are integrated.

\section{Acknowledgment}

This work was financially supported by the SGCC technology project of the Deepen Technology Research on New Generation Smart Substation Network Communication and Protectio n.

\section{References}

[1] XU Xiaohui. Introduction to smart grid[M]. Beijing: China Power Publications,2009.

[2] DL / T 860 - 2006. Substation communication network and system [S]. Beijing: China Power Publications,2006.

[3] State Grid. Technical guide for smart substation[Z]. Beijing: State Grid,2009.

[4] LI Mengcha, WANG Yunping, LI Xianwei, WANG Feng, CAI Weifeng.Smart substation and technical characterisfics analysis[J]. Power System Protection and Control, 2010,38(18):5962,79

[5] XIN Peizhe, YAN Peili, XIAO Zhihong, LIU Ying, WANG Yudong, ZOU Guohui. Application of Communication Network Technology in New Generation Smart Substation[J]. Electric Power Construction,2013,34(7):17-23 